\title{
An Improved Model for the Estimation of Solar Radiation from Satellite Data for Thailand
}

\author{
Serm Janjai*, Itsara Masiri, Somjet Pattarapanitchai, Jarungsaeng Laksanaboonsong \\ Solar Energy Research Laboratory, Department of Physics, Faculty of Science, \\ Silpakorn University, Nakhon Pathom, Thailand, 73000
}

\begin{abstract}
This paper presents an improved model for estimating surface solar radiation from satellite data for Thailand. Digital data from the visible channel of the GOES9 and MTSAT-1R satellites were used as the main input data of the model. This model accounted for the scattering of solar radiation by clouds, absorption of solar radiation by water vapour, ozone and gases and solar radiation depletion by aerosols. Additionally, the multiple reflections between the atmosphere and the ground in satellite band, which were ignored in the original model, were included in the improved model. For testing its validity, the model was employed to calculate monthly average daily global solar radiation at 38 solar monitoring stations in Thailand. It was found that the solar radiation calculated from the model and that obtained from the measurements were in good agreement, with a root mean square difference (RMSD) of $6.1 \%$ and mean bias difference (MBD) of $0.3 \%$. The performance of the improved model was better than that of the original model.
\end{abstract}

\section{Introduction}

Information on the amount of solar radiation at the earth's surface is essential for designing solar energy conversion systems. Ideally, such information should be obtained from a dense network of solar radiation monitoring stations covering an area of interest. However, in reality the number of stations in the network of most countries is too sparse to provide sufficient data for solar energy applications.

As cloud is a main factor affecting solar radiation on the earth's surface and meteorological satellites can detect the cloud, it is possible to use satellite data to derive solar radiation. In the past 30 years, a number of models have been proposed to derive solar radiation from satellite data. (e.g. Gautier et al., 1980; Tarpley, 1979; Cano et al., 1986; Cogliani et al., 2007). These models have different degrees of a complexity and accuracy. Additionally, most of these models were developed for mid-latitude zones. Published reports on satellite models for the tropics are very limited. Although we have developed a satellite-based solar radiation model for calculating solar radiation in Thailand (Janjai et al., 2005), several assumptions were made to simplify the calculation. Additionally, the model validation was carried out against measured solar radiation from only 4 solar monitoring stations. Therefore, the objective of this work was to improve our previous model (Janjai et al., 2005). The improved model accounted for the effect of the absorption of solar radiation in the upwelling path and the multiple scattering between the ground and the atmosphere in the satellite band, which were ignored in our previous model. This improved model was validated against measured solar radiation from 38 stations in Thailand. 


\section{Methodology}

The methodology of this work consists of processing of satellite data, formulation of the model, calculation of model parameters and model validation. The details of these steps are as follows.

\subsection{Processing of satellite data}

The satellite images used in this work were presented in an 8-bit digital format. They were visible data obtained from GOES9 (June, 2003 - July, 2005) and MTSAT-1R (August, 2005 December, 2009).

Nine hourly images per day $(8: 30 \mathrm{am}-4.30 \mathrm{pm})$ were used in this work. When displayed as images, the digital data covered the entire areas of Thailand with a spatial resolution of $3 \times 3$ $\mathrm{km}^{2}$. These images were transformed into a cylindrical projection, being linear in latitude and longitude. Then they were navigated by using features of the coastline as a reference. Each image consists of a matrix of $500 \times 800$ pixels representing the solar radiation reflected from the earthatmospheric system in the form of gray levels $(0-255)$. The values of the gray level were transformed into the earth-atmospheric reflectivity $\left(\rho_{\mathrm{EA}}^{\prime}\right)$ using calibration tables provided by Japan Meteorological Agency. This reflectivity will be used as the main input of the satellite model.

\subsection{Formulation of the model}

The improved model considered absorption and scattering processes due to clouds, ozone, aerosols, water vapour and other gases in the atmosphere both for the upwelling and downwelling paths of solar radiation. The multiple reflection between the atmosphere and the ground was also taken into account in this model. Note that the absorption and scattering of solar radiation in the upwelling path and the multiple reflection were not included in the previous model (Janjai et al., 2005). The absorption and scattering of solar radiation in the earth-atmospheric system of the improved model are schematically shown in Fig. 1.

Consider a unit of the downwelling solar radiation entering the earth's atmosphere, part of it is scattered to the outer space by clouds, air molecules and aerosols (see Fig 1). The scattering due to clouds, air molecules and aerosols in the atmosphere can be represented in terms of reflection coefficients $\left(\rho_{\mathrm{A}}^{\prime}+\rho_{\text {aer }}^{\prime}\right)$, hence the remaining portion of radiation in its path is $1-\rho_{\mathrm{A}}^{\prime}-\rho_{\text {aer }}^{\prime}$. Note that the scattering of clouds and air molecule is represented by one coefficient, $\rho_{A}^{\prime}$. From this point, the rest of the downwelling radiation is absorbed by ozone, gases, water vapour and aerosols with the absorption coefficients of $\alpha_{\mathrm{o}}^{\prime}, \alpha_{\mathrm{g}}^{\prime}, \alpha_{\mathrm{w}}^{\prime}$ and $\alpha_{\mathrm{aer}}^{\prime}$, respectively. The remaining solar radiation arriving at the ground is $\left(1-\rho_{A}^{\prime}-\rho_{\text {aer }}^{\prime}\right)$ $\times\left(1-\alpha_{\mathrm{w}}^{\prime}-\alpha_{\mathrm{o}}^{\prime}-\alpha_{\mathrm{aer}}^{\prime}-\alpha_{\mathrm{g}}^{\prime}\right)$. This solar radiation is then reflected back to the atmosphere by the ground with the surface albedo of $\rho_{\mathrm{G}}^{\prime}$. Part of the reflected solar radiation is again absorbed by aerosols and scattered by clouds, air molecules and aerosols. Hence, part of radiation leaving the atmosphere to the outer space from the first incident solar radiation is written as $\left(1-\rho_{\mathrm{A}}^{\prime}-\rho_{\mathrm{aer}}^{\prime}\right)^{2} \times\left(1-\alpha_{\mathrm{w}}^{\prime}-\alpha_{\mathrm{o}}^{\prime}-\alpha_{\mathrm{aer}}^{\prime}-\alpha_{\mathrm{g}}^{\prime}\right)^{2} \rho_{\mathrm{G}}^{\prime}$. The remaining portion is reflected back 
to the ground by clouds, air molecules and aerosols. Then the process is repeated. The sum of all solar radiation leaving the atmosphere to the outer space is called earth-atmospheric reflectivity $\left(\rho_{\mathrm{EA}}^{\prime}\right)$. It is observed by the satellite and can be written as:

$$
\rho_{\mathrm{EA}}^{\prime}=\rho_{\mathrm{A}}^{\prime}+\rho_{\mathrm{aer}}^{\prime}+\frac{\left(1-\rho_{\mathrm{A}}^{\prime}-\rho_{\mathrm{aer}}^{\prime}\right)^{2}\left(1-\alpha_{\mathrm{w}}^{\prime}-\alpha_{\mathrm{o}}^{\prime}-\alpha_{\mathrm{aer}}^{\prime}-\alpha_{\mathrm{g}}^{\prime}\right)^{2} \rho_{\mathrm{G}}^{\prime}}{1-\left(\rho_{\mathrm{A}}^{\prime}+\rho_{\mathrm{aer}}^{\prime}\right)\left(1-\alpha_{\mathrm{w}}^{\prime}-\alpha_{\mathrm{o}}^{\prime}-\alpha_{\mathrm{aer}}^{\prime}-\alpha_{\mathrm{g}}^{\prime}\right)^{2} \rho_{\mathrm{G}}^{\prime}}
$$

where $\rho_{\mathrm{EA}}^{\prime}$ is earth-atmospheric reflectivity in the satellite wavelength band or narrow-band wavelength, $\rho_{\mathrm{A}}^{\prime}$ is atmospheric reflectivity due to the scattering of clouds and air molecules in satellite band, $\rho_{\text {aer }}^{\prime}$ is scattering coefficient of aerosols in satellite band,$\alpha_{\text {aer }}^{\prime}$ is absorption coefficient of aerosols in satellite band, $\alpha_{\mathrm{w}}^{\prime}$ is absorption coefficient of water vapour in satellite band, $\alpha_{\mathrm{o}}^{\prime}$ is absorption coefficient of ozone in satellite band, $\alpha_{\mathrm{g}}^{\prime}$ is absorption coefficient of gases in satellite band and $\rho_{\mathrm{G}}^{\prime}$ is surface albedo in satellite band.

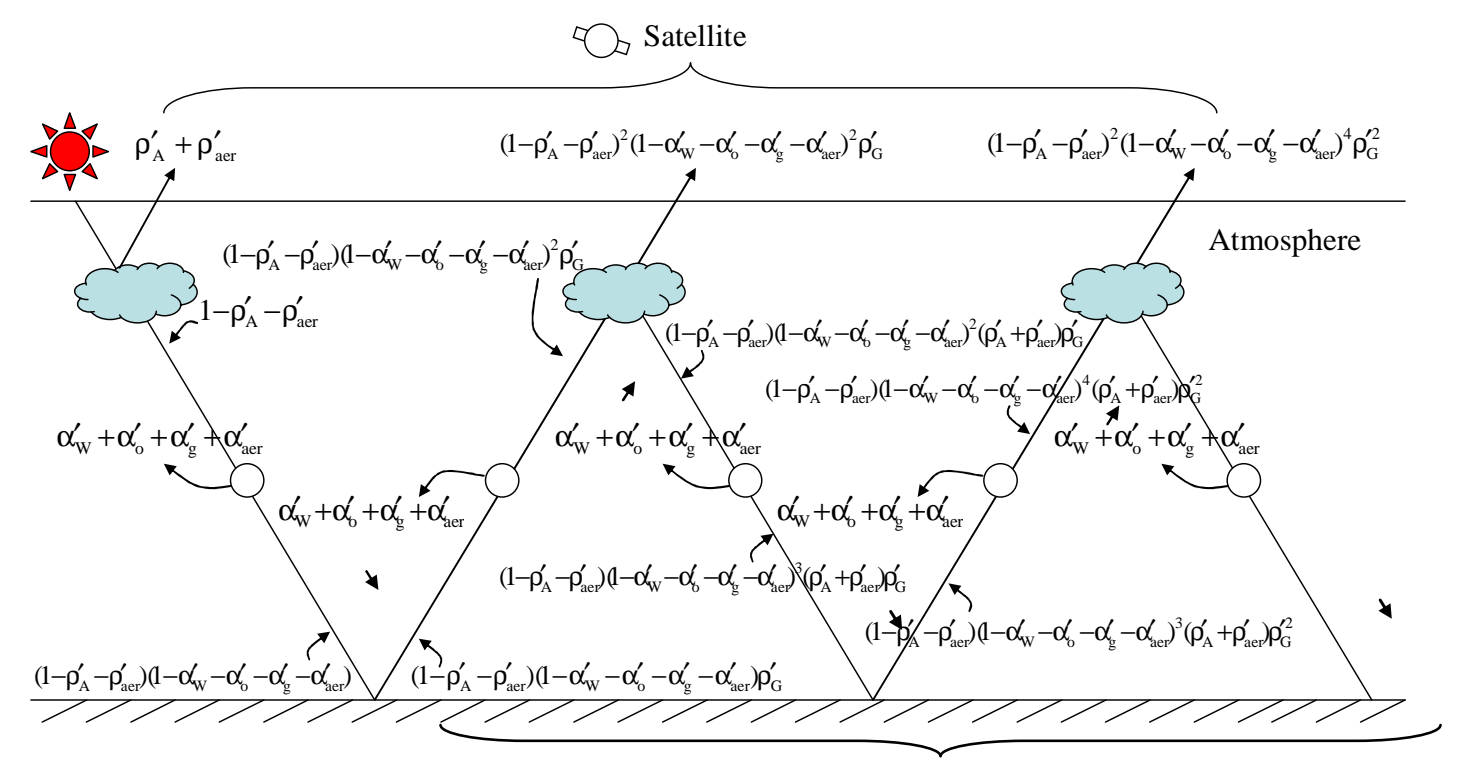

Fig. 1: Schematic diagram of the radiation budget as seen by the satellite in the improved model ( $\alpha_{\mathrm{o}}^{\prime}=$ absorption coefficient of ozone, $\alpha_{\mathrm{w}}^{\prime}=$ absorption coefficient of water vapour, $\alpha_{\text {aer }}^{\prime}=$ absorption coefficient of aerosols, $\alpha_{\mathrm{g}}^{\prime}=$ absorption coefficient of atmospheric gases, $\rho_{\mathrm{A}}^{\prime}=$ atmospheric reflectivity due to clouds and air molecules, $\rho_{\text {aer }}^{\prime}=$ scattering coefficient of aerosols,

$$
\rho_{\mathrm{G}}^{\prime}=\text { surface albedo, } \alpha_{\mathrm{EA}}^{\prime}=\text { earth-atmospheric reflectivity) }
$$

Rearranging Eq. (1) yields: 


$$
\rho_{\mathrm{A}}^{\prime}=\frac{\mathrm{A}-\mathrm{AC}+\mathrm{ABC}+\mathrm{BC}^{2}}{\mathrm{C}-1+\mathrm{BC}+\mathrm{AC}}
$$

where

$$
\begin{aligned}
& \mathrm{A}=\rho_{\mathrm{aer}}^{\prime}-\rho_{\mathrm{EA}}^{\prime} \\
& \mathrm{B}=1-\rho_{\mathrm{aer}}^{\prime} \\
& \mathrm{C}=\left(1-\alpha_{\mathrm{w}}^{\prime}-\alpha_{\mathrm{o}}^{\prime}-\alpha_{\mathrm{aer}}^{\prime}-\alpha_{\mathrm{g}}^{\prime}\right)^{2} \rho_{\mathrm{G}}^{\prime}
\end{aligned}
$$

From Eq. (2), $\rho_{\mathrm{EA}}^{\prime}$ is obtained from satellite data, $\rho_{\mathrm{aer}}^{\prime}, \quad \alpha_{\mathrm{w}}^{\prime}$ and $\alpha_{\mathrm{g}}^{\prime}$ can be derived from ground-based measurements. The surface albedo $\rho_{\mathrm{G}}^{\prime}$ and ozone absorption coefficient $\alpha_{\mathrm{o}}^{\prime}$ are also derived from satellite data. The method for deriving these coefficients is explained in the next section. Therefore, values of $\rho_{A}^{\prime}$ can be calculated from Eq. (2). In the next step $\rho_{A}^{\prime}$, which is in satellite band (0.55-0.90 $\mu \mathrm{m}$ for MTSAT-1R and 0.50-0.75 for GOES9), is converted into broadband atmospheric albedo $\left(\rho_{\mathrm{A}}: 0.3-3.0 \mu \mathrm{m}\right)$ using empirical formula explained in the next section. Then broadband atmospheric albedo $\left(\rho_{A}\right)$ is used to calculate broadband atmospheric transmittance, which is expressed as:

$$
\tau=\frac{\left(1-\rho_{\mathrm{A}}-\rho_{\mathrm{aer}}\right)\left(1-\alpha_{\mathrm{w}}-\alpha_{\mathrm{o}}-\alpha_{\mathrm{aer}}-\alpha_{\mathrm{g}}\right)}{1-\rho_{\mathrm{G}}\left(\rho_{\mathrm{A}}+\rho_{\mathrm{aer}}\right)\left(1-\alpha_{\mathrm{w}}-\alpha_{\mathrm{o}}-\alpha_{\mathrm{aer}}-\alpha_{\mathrm{g}}\right)^{2} \rho_{\mathrm{G}}}
$$

where $\tau$ is broadband transmittance of the atmosphere, $\rho_{\mathrm{A}}$ is atmospheric reflectivity due to the scattering of clouds and air molecules in broadband, $\rho_{\text {aer }}$ is scattering coefficient of aerosols in broadband, $\alpha_{\text {aer }}$ is absorption coefficient of aerosols in broadband, $\alpha_{w}$ is absorption coefficient of water vapour in broadband, $\alpha_{0}$ is absorption coefficient of ozone in broadband, $\alpha_{\mathrm{g}}$ is absorption coefficient of gases in broadband and $\rho_{\mathrm{G}}$ is surface albedo in broadband.

The denominator term represents the multiple reflections between the ground and the atmosphere. The values of $\rho_{\mathrm{G}}, \rho_{\mathrm{aer}}, \alpha_{\mathrm{aer}}, \alpha_{\mathrm{o}}$ and $\alpha_{\mathrm{w}}$ can be calculated using ground and satellite based data as explained in the next section. Therefore, values of $\tau$ are obtained from Eq. (3). These values are finally employed to compute solar radiation incident on the ground using the following equation.

$$
\mathrm{H}=\tau \mathrm{H}_{0}
$$

where $\tau$ is solar radiation transmittance coefficient of the atmosphere, $\mathrm{H}$ is daily irradiation on the earth's surface and $\mathrm{H}_{0}$ is extraterrestrial daily irradiation. $\mathrm{H}_{0}$ was calculated by using the formula reported in Iqbal (1983). In calculating $\mathrm{H}_{0}$ from this formula, a solar constant of 1366.1 
$\mathrm{W} / \mathrm{m}^{2}$ was used (ASTM, 2000). All parameters of the model were determined using monthly average daily basis.

\subsection{Calculation of model parameters}

\subsubsection{Surface albedo $\left(\rho_{\mathrm{G}}\right)$}

The surface albedo was estimated from satellite images collected at 12:30 h local time. For each month, digital data of rectified images were examined and pixels with the lowest gray level value were selected to create the cloud-free composite image for that month. All cloud-free composite images were then transformed into cloud-free earth-atmospheric reflectivity by using the conversion table. The effect of the atmospheric reflectivity is removed from the cloud-free earthatmospheric albedo by using 6S radiative transfer model (Vermote et al., 1997).

The $6 \mathrm{~S}$ is a radiative transfer model which can be used to simulate the solar radiation reflected from the earth-atmospheric system to satellites under a clear sky condition. We used the $6 \mathrm{~S}$ to formulate a statistical relation between the cloud-free earth atmospheric albedo to the surface albedo. Then this relation was employed to calculate the surface albedo from the cloud-free earth-atmospheric albedo all over the country.

\subsubsection{Absorption coefficient of water vapour}

The amount of atmospheric water vapour is usually quantified as a thickness (in $\mathrm{cm}$ ) of precipitable water. The absorption coefficient of water vapour can be determined by the followings Eqs.:

- in satellite band

$$
\alpha_{\mathrm{w}}^{\prime}=1-\frac{\int_{\lambda_{1}}^{\lambda_{2}} \mathrm{I}_{0 \lambda} \tau_{\mathrm{w} \lambda} \mathrm{d} \lambda}{\int_{\lambda_{1}}^{\lambda_{2}} \mathrm{I}_{0 \lambda} \mathrm{d} \lambda}
$$

- in broadband

$$
\alpha_{w}=1-\frac{\int_{0.3}^{3.0} \mathrm{I}_{0 \lambda} \tau_{\mathrm{w} \lambda} \mathrm{d} \lambda}{\int_{0.3}^{3.0} \mathrm{I}_{0 \lambda} \mathrm{d} \lambda}
$$

where $I_{0 \lambda}$ is extraterrestrial spectral irradiance, $\tau_{w \lambda}$ is spectral transmittance of water vapour,

$\alpha_{w}^{\prime}$ is absorption coefficient of water vapour in satellite band, $\alpha_{w}$ is absorption coefficient of water vapour in broadband, and $\lambda_{1}, \lambda_{2}$ are wavelength bands of the satellite. Transmittance of water vapour) $\tau_{\mathrm{w} \lambda}$ (is determined using the formula in Iqbal (1983). The temperature and relative humidity data collected at 85 meteorological stations over Thailand were used to estimate 
precipitable water by using the formula proposed by Janjai et al. (2005). These data were extrapolated to cover the entire areas of the country.

\subsubsection{Absorption coefficient of ozone}

In this work, the absorption coefficients due to ozone were calculated from the following equations.

- in satellite band

$$
\int_{\lambda}^{\lambda_{2}} \mathrm{I}_{0 \lambda} \tau_{\mathrm{o} \lambda} \mathrm{d} \lambda
$$

- in broadband

$$
\alpha_{\mathrm{o}}^{\prime}=1-\frac{\lambda_{1}}{\int_{\lambda_{1}}^{\lambda_{2}} \mathrm{I}_{0 \lambda} \mathrm{d} \lambda}
$$

$$
\alpha_{0}=1-\frac{\int_{0.3}^{3.0} \mathrm{I}_{0 \lambda} \tau_{\mathrm{o} \lambda} \mathrm{d} \lambda}{\int_{0.3}^{3.0} \mathrm{I}_{0 \lambda} \mathrm{d} \lambda}
$$

where $\alpha_{0}^{\prime}$ is absorption coefficient of ozone in satellite band, $\alpha_{0}$ is absorption coefficient of ozone in broadband and $\tau_{\mathrm{o} \lambda}$ is spectral transmittance of ozone. Spectral transmittance coefficient of ozone was calculated by using a model reported by Iqbal (1983). The total column ozone from TOMS/EP and OMI/Aura satellites were used for the calculation of the spectral transmittance coefficient. The TOMS data were based on version 8 algorithm whereas the OMI data were based on the maximum likelihood estimation technique (www.macuv.gsfc.nasa.gov).

\subsubsection{Absorption coefficient of atmospheric gases}

The relationship described by Iqbal (1983) for spectral transmission $\left(\tau_{\mathrm{g} \lambda}\right)$ after absorption by carbon dioxide, oxygen and other trace gases was used to calculate the spectral transmittance. The absorption coefficient of gases was calculated from the spectral transmittance as:

- in satellite band

$$
\alpha_{\mathrm{g}}^{\prime}=1-\frac{\int_{\lambda_{1}}^{\lambda_{2}} \mathrm{I}_{0 \lambda} \tau_{\mathrm{g} \lambda} \mathrm{d} \lambda}{\int_{\lambda_{1}}^{\lambda_{2}} \mathrm{I}_{0 \lambda} \mathrm{d} \lambda}
$$

- in broadband

$$
\alpha_{g}=1-\frac{\int_{0.3}^{3.0} \mathrm{I}_{0 \lambda} \tau_{\mathrm{g} \lambda} \mathrm{d} \lambda}{\int_{0.3}^{3.0} \mathrm{I}_{0 \lambda} \mathrm{d} \lambda}
$$


where $\alpha_{\mathrm{g}}^{\prime}$ is absorption coefficient of gases in satellite band, $\alpha_{\mathrm{g}}$ is absorption coefficient of gases in broadband and $\tau_{\mathrm{g} \lambda}$ is spectral transmittance of gases.

\subsubsection{Solar radiation depletion by aerosols}

Aerosols are fine solid or liquid particles which suspend in the atmosphere. The aerosols play an important role in depleting solar radiation within the polluted atmosphere. Aerosol properties in the atmosphere can be measured by using ground-based instruments such as sunphotometers. However, it is costly to deploy such instruments over a large area. The amount of aerosols has an inverse relationship to values of visibility. The more aerosols exist in the atmosphere, the lower visibility is observed. Therefore, visibility was used to quantify the effect of aerosols on solar radiation in this study. Visibility data observed at 85 meteorological stations across Thailand were used in this work. They were also extrapolated to cover the entire areas of the country.

The depletion of solar radiation due to aerosols can be estimated from the visibility data. A relationship between the visibility data and the depletion due to aerosols, which was developed by Janjai et al. (2005) was used in this work. This relationship is written as:

$$
\mathrm{D}_{\mathrm{aer}}=0.3631-0.0222(\mathrm{VIS})+0.0003(\mathrm{VIS})^{2}
$$

where $\mathrm{D}_{\text {aer }}$ is solar radiation depletion coefficient due to aerosols and VIS is visibility in $\mathrm{km}$.

The depletion of solar radiation caused by aerosols $\left(\mathrm{D}_{\mathrm{aer}}\right)$ is a result of absorption and scattering processes. To determine the scattering and absorption effects, single scattering albedo data (SSA) provided by AERONET (Aerosol Robotic Network of NASA) were collected from eighty-two sites located across East Asia. The data were used to determine the proportion between the scattering and absorption caused by aerosols over Thailand. The absorption and scattering fractions were interpolated over the entire areas of Thailand. Using these fractions, the scattering coefficient $\left(\rho_{\text {aer }}\right)$ and absorption coefficients $\left(\alpha_{\text {aer }}\right)$ were determined.

\subsubsection{Broadband atmospheric reflectivity $\left(\rho_{A}\right)$}

The broadband atmospheric reflectivity $\left(\rho_{A}\right)$ is required for the calculation of the surface solar radiation. However, the satellite gives only the satellite band reflectivity $\left(\rho_{\mathrm{A}}^{\prime}\right)$. We proposed to convert $\rho_{\mathrm{A}}^{\prime}$ into $\rho_{\mathrm{A}}$ by using statistical relations derived from solar radiation data collected from solar radiation monitoring stations of Silpakorn University at Chiang Mai $\left(18.78{ }^{\circ} \mathrm{N}, 98.98{ }^{\circ} \mathrm{E}\right)$, Ubon Ratchathani $\left(15.25^{\circ} \mathrm{N}, 104.87^{\circ} \mathrm{E}\right)$, Nakhon Pathom (13.82 $\left.{ }^{\circ} \mathrm{N}, 100.04{ }^{\circ} \mathrm{E}\right)$ and Songkhla $\left(7.20^{\circ} \mathrm{N}, 100.60^{\circ} \mathrm{E}\right)$. The effects of multiple reflection were taken into account in the relations. Details of the formulation of the statistical relations are described in Janjai (2010) these relations are as follows.

For GOES 9

For MTSAT-1R

$$
\rho_{\mathrm{A}}=0.8824 \rho_{\mathrm{A}}^{\prime}+0.1615
$$$$
\rho_{\mathrm{A}}=0.8795 \rho_{\mathrm{A}}^{\prime}+0.2380
$$ 


\subsection{Model validation}

To validate its performance, the improved model was used to calculate solar radiation at the positions of 38 solar monitoring stations in Thailand. The periods of solar radiation data are 5-7 years, depending on the stations. Values of monthly mean daily global solar radiation averaged over these periods were used in the validation. The values of solar radiation calculated form the models were then compared with those obtained from the measurements and the results are shown in Fig. 2.

From Fig. 2, it is observed that the discrepancies between the measured and calculated solar radiation in terms of root mean square difference (RMSD) and mean bias difference (MBD) are $6.1 \%$ and $0.3 \%$, respectively. For our previous model (Janjai et al., 2005), the RMSD and MBD were reported as $6.8 \%$ and $2.7 \%$, respectively. This result indicates that improved model has better performance than our previous model.

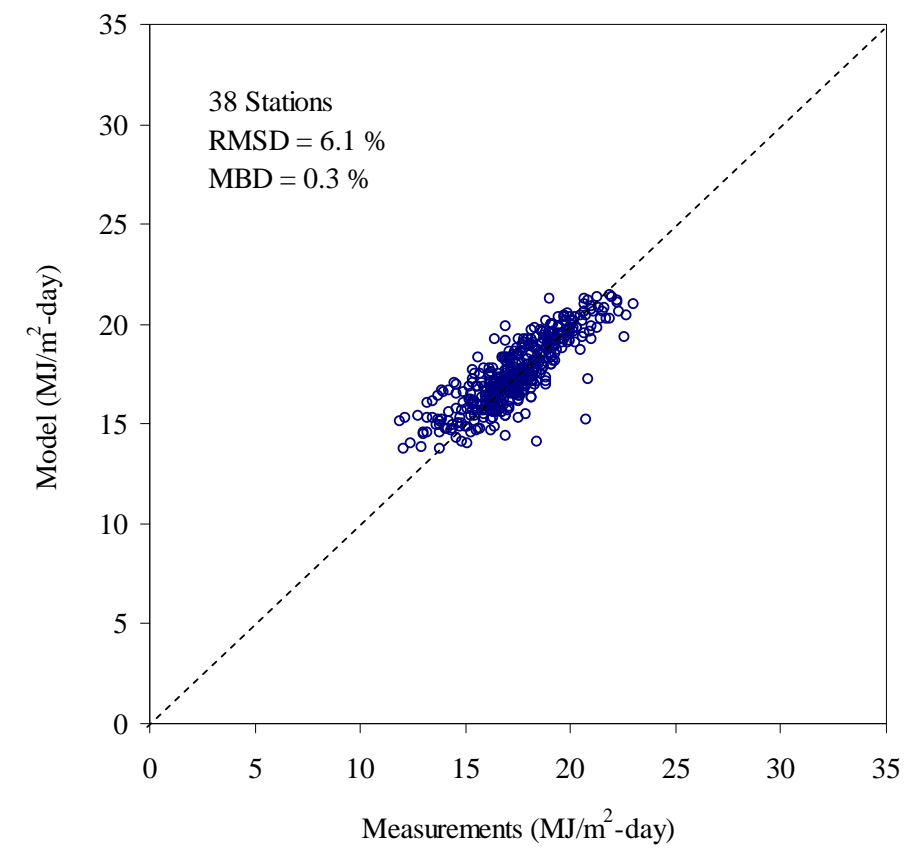

Fig. 2: Comparison between the monthly average daily global radiation from the model and from the measurements at 38 stations.

\section{Conclusion}

A model for estimating solar radiation from satellite data for Thailand has been improved. The absorption of solar radiation in the upwelling path and the multiple reflection which were ignored in the original model (Janjai et al., 2005) were taken into account in the improved model. The improved was validated against solar radiation measured at 38 solar monitoring stations in Thailand. It was found that solar radiation calculated from the model and that obtained from the 
measurements were in good agreement, with the discrepancy in terms of root mean square difference and mean bias difference of $6.1 \%$ and $0.3 \%$, respectively. The improved model showed better performance than the original model.

\section{Acknowledgement}

The authors would like to thank the Department of Alternative Energy Development and Efficiency, Ministry of Energy of Thailand for inviting Silpakorn University to carry out this work. 


\section{REFERENCES}

[1] ASTM, Standard solar constant and zero air mass solar spectral table, Standard E-490-00 American Society for Testing and materials, West Conshohocken, PA (2000)

[2] Cano D., Monget J. M., Albuisson M., Gurnard H., Regas N., Wald L., A method for the determination of the global solar radiation from meteorological satellite data, Solar Energy, 37, 31-39, 1986.

[3] Cogliani E., Ricchiazzi P., Maccari A., Physical model SOLARMET for determinating total and direct solar radiation by meteosat satellite images, Solar Energy, 81, 791-798, 2007.

[4] Gautier C., Diak G., Masse S., A simple physical model to estimate incident solar radiation at the surface from GOES satellite data, Journal Applied Meteorology, 36, 1005-1012, 1980.

[5] Iqbal M., An introduction to solar radiation, Academic Press, New York, 1983.

[6] Janjai S., Laksanaboonsong J., Nunez M., Thongsathitya A., Development of a method generating operational solar radiation maps from satellite data for a tropical environment, Solar Energy, 78, 739-751, 2005.

[7] Janjai S., Solar Radiation Maps from Satellite Data for Thailand, Report, Department of Alternative Energy Development and Efficiency, Bangkok, 2010.

[8] Janjai, S., Wanvong, W., Laksanaboonsong, J. The determination of surface albedo of Thailand using satellite data, In Proceeding of the $2^{\text {nd }}$ Joint International Conference on Sustainable Energy and Environment (SEE2006) Bangkok, Thailand, pp. 156-161 (2006).

[9] Tarpley, J.D., Estimating incident solar radiation at the surface from geostationary satellite data, Journal of Applied Meteorology, 18, 1172-1181 (1979).

[10] Vermote E. F., Tanrè D., Deuzè' J. L., Herman M., Morcrette J. J., Second simulation of the satellite signal in the solar spectrum, 6S: An overview. IEEE Trans. Geosci. Remote Sens., 35, 675-686, (1997). 